J. Lake Sci. (湖泊科学), 2006, 18(2) : 184-188

http:// www. jlakes. org. E-mail: jlakes@ niglas. ac.cn

(c) 2006 by Journal of Lake Sciences

\title{
五株微囊藻毒素降解菌的分离与鉴定”
}

\author{
宦海琳, 韩 岚, 李建宏 ${ }^{* *}$, 翁永萍
}

（南京师范大学, 江苏省生物多样性与生物技术重点实验室, 南京 210097)

\begin{abstract}
摘 要: 有毒蓝藻产生的蓝藻毒素导致地表水的污染已是全球普遍的现象, 最常见的毒素是能导致肝癌的肝毒素微囊藻 毒素 (MC), 迄今为止尚无适用的 MC 驱除技术, 微生物降解 MC 可能是一条有效的途径. 本研究以铜绿微囊藻 (Microcystis aeruginosa PCC 7806) 所产生的 MC 为底物, 从多个形成微囊藻水华的水体中分离获得能显著降解 MC 的细菌 18 株, 相对 降解能力从 $18.4 \%$ 到 $48.2 \%$. 对其中 5 株 MC 相对降解能力较强的菌, 通过形态特征和生理生化特征分析, 鉴定出 5 株菌 分别为: 不动细菌属 (Acinetobacter)、肠杆菌属 (Enterobacter)、微杆菌属 (Microbacterium)、芽孢杆菌属 (Bacillus) 和弗拉特氏 菌属 (Frateuria) ,均不同于已报道的属种.
\end{abstract}

关键词: 微囊藻毒素; 细菌降解; 水华; 蓝藻毒素

\section{Isolation and identification of five microcystin degrading bacterial strains}

HUAN Hailin, HAN Lan, LI Jianhong \& WENG Yongping

( Nanjing Normal University, Key Lab of Biodiversity and Biotechnology of Jiangsu Province, Nanjing 210097 P. R. China)

Abstract: Cyanotoxins produced by cyanobacteria have caused pollutions in land surface water around the world. The most common toxin is microcystin (MC), a cancer inducing hepatoxin. No effective technology could be used to remove it up to now. Microbiological degradation should be a suitable way. In this study, we used BG-11 medium to culture Microcystis aeruginosa PCC 7806 in the library . MC was extracted by 70\% methanol, then concentrated and purified by $\mathrm{C}_{18}$ solid-phase extraction collum. The relative contents of MC-LR and MC-RR were 68.2\% and $9.3 \%$, respectively, on the basis of high performance liquid chromatography (HPLC) analysis. We used this MC as selective substrate to isolate MC degradable bacteria. From cyanobacterial bloom forming water body such as Xuanwu Lake, Qinhuai Rever, we got eighteen bacterial strains, which could degrade MC-LR obviously. The relative efficiencies were from $18.4 \%$ to $48.2 \%$. Five more effective strains of them were identified as Acinetobacter, Enterobacter, Microbacterium, Bacillus and, Frateuria, respectively by there morphology and biochemical characteristics. These strains were all different from the published ones up to now.

Keywords: Microcystin; bacterial degradation; cyanobacterial bloom; cyanotoxin

由于环境污染, 近年来水体富营养化程度日益加剧, 蓝藻水华频繁爆发. 许多蓝藻产生毒素释放到水体 中, 其中微囊藻毒素 (microcystins, MC) 是分布最广、危害最严重的一类. 微囊藻毒素是环状七肽肝毒素, 它 对蛋白磷酸酶 1 和 $2 \mathrm{~A}$ 起抑制作用, 具有诱发肝癌的作用. MC 在水体中的存在, 给饮水安全造成了严重的 威胁 ${ }^{[1,2]} .1998$ 年 WHO 年出版的《饮用水卫生基准》增补版和 2001 年卫生部颁布的《生活饮用水卫生 规 范》中均设定饮用水中总 MC-LR 浓度暂行基准值为 $1 \mu \mathrm{g} / \mathrm{L}^{[3,4]}$.

为消除水体中的 $\mathrm{MC}$,一些研究者对活性炭吸附、光降解与光催化氧化、臭氧氧化、化学药剂氧化、膜过 滤等技术进行了研究 ${ }^{[5]}$, 但到目前为止尚无有效应用技术. 微生物降解技术是一条可用的途径. 天然水体

* 教育部归国留学人员基金(2003) 和江苏省教委基金(03KJB180113) 联合资助. $2005-05-07$ 收稿;2005 - 07 - 15 收修改稿. 宦海琳,女, 1981 年生, 硕士研究生.

**通讯作者: 李建宏, E-mail: lijianhong@ njnu. edu. cn. 
中广泛存在着能够降解 MC 的微生物, 在污水沟、湖水、沉积物和河水中均已发现降解 MC 的土著菌 ${ }^{[6]}$. MC 的环状结构和间隔双键有相当的稳定性,一般的多肽水解酶不能对 MC 进行降解, 只有一些特殊的微生物 菌种具备对 MC 的降解能力. 已报道的菌株有: 鞘氨醇单胞菌属 (Sphingomonas)、铜绿假单胞菌 (Pseudomonas aeruginosa)、青枯菌 (Ralstonia solanacearum) 等 ${ }^{[7-10]}$.

尽管 MC 降解菌普遍存在, 然而迄今为止, 从自然水体中分离纯化的 MC 降解菌的研究还非常有限, 为 此本研究对降解 MC 微生物菌种进行了笁选和研究.

\section{1 材料与方法}

\section{1 实验仪器与试剂}

铜绿微囊藻 (Microcystis aeruginosa PCC 7806) 由法国国家科学研究中心 LCB - CNRS 张承才教授惠赠. 微囊藻毒素标样 MC - LR, MC - RR, 由中国科学院水生生物研究所提供.

高效液相色谱仪 (Agilent, 自带液相色谱化学工作站); Hypersil ODS 色谱柱 (Agilent, $4.0 \times 250 \mathrm{~mm}$ ); 自制 $\mathrm{C}_{18}$ 固相萃取小柱.

\subsection{MC 的提取与纯化}

使用 BG11 培养基大量培养铜绿微囊藻, 收集藻细胞, 70\% 甲醇提取, 取上清液, 用 $\mathrm{C}_{18}$ 柱净化浓缩, 浓 缩液经 $0.45 \mu \mathrm{m}$ 滤膜过滤除菌后, 保存于冰箱中作为实验用 $\mathrm{MC}$ 的储备液 ${ }^{[11]}$.

\subsection{MC 的测定}

样品经 $0.45 \mu \mathrm{m}$ 微孔滤膜过滤, HPLC 测定 MC 的浓度. 测定条件是: 流动相 $55 \%$ 甲醇 $45 \% 0.05 \mathrm{M} \mathrm{H}_{3}$ $\mathrm{PO}_{4} / \mathrm{KH}_{2} \mathrm{PO}_{4}$, 流速 $1.0 \mathrm{ml} / \mathrm{min}$, 紫外检测波长 $238 \mathrm{~nm}$, 进样量 $20 \mu \mathrm{l}$, 依据保留时间定性,外标法定量.

\section{4 微生物菌种的篮选与活性测定}

分别从发生微囊藻水华的养殖池塘、玄武湖、秦淮河中采集水样, 菌种培养选用 M9 培养基 ${ }^{[12]}$ 为基础 培养基, 添加提取纯化的 MC 作为底物来篮选菌种.

水样稀释涂布于篮选的固体培养基上,在 $30^{\circ} \mathrm{C}$ 培养 $1-3 \mathrm{~d}$ 后, 挑取大的单菌落再在篮选培养基上划线 分离,重复 3-4 次,选取长势良好的单菌落进行下一步的液体篮选.

将篮选的各株菌接种到 $\mathrm{M} 9$ 培养基中, $30^{\circ} \mathrm{C}$ 培养 $1 \mathrm{~d}\left(\mathrm{OD}_{600}=0.90-1.10\right)$, 取 $1 \mathrm{ml}$ 离心收集菌体, 分别 加到含 MC( MC-LR 的初始浓度为 $15 \mathrm{mg} / \mathrm{L})$ 的 $5 \mathrm{ml} \mathrm{M}$ 培养基中, $30^{\circ} \mathrm{C}$ 培养 $2 \mathrm{~d}$, 上清液用 HPLC 分析.

\section{5 微生物菌种的鉴定}

将分离纯化的 5 株 MC 降解菌菌株进行菌体形态、染色反应、培养性状和生理生化测定,根据《伯杰氏 细菌鉴定手册》第八版等其他文献进行鉴定 ${ }^{[13-15]}$.

\section{2 结果}

\subsection{MC 的提取纯化}

图 1 是 $10 \mathrm{mg} / \mathrm{L}$ 标准品和从培养的铜绿微囊藻细胞 中提取提纯 MC-RR 和 MC-LR 的 HPLC 图谱, 图中显示 MC-RR 和 MC-LR 的保留时间分别为 $13.82 \mathrm{~min}$ 和 23.91 $\min$,与提纯 MC-RR 和 MC-LR 的保留时间 $13.74 \mathrm{~min}$ 和 $23.90 \mathrm{~min}$ 一致. 经测定提取获得的 MC-RR 和 MC-LR 的 浓度分别为 $34.6 \mathrm{mg} / \mathrm{L}$ 和 $328.2 \mathrm{mg} / \mathrm{L}$, 相对含量分别为 $9.3 \%$ 和 $68.2 \%$ 左右, 主要是 MC-LR, 可以此作为底物进 行篮选降解菌的实验.

\subsection{MC-LR 降解菌的篮选}

用 MC 作为底物篮选微生物, 经多次篮选从平板上 挑取了 127 个单菌落, 进一步在笁选培养基上划线分离, 3 次后, 选取了其中 53 个长势良好的单菌落, 进行 MC 降
表 1 不同菌株对 MC-LR 的降解率

Tab. 1 Relative degrading ratio of MC-LR by different bacterial strains

\begin{tabular}{cccc}
\hline 菌株 & 降解率 $(\%)$ & 菌株 & 降解率 $(\%)$ \\
\hline L1 & 27.5 & N1 & 41.0 \\
L2 & 28.4 & N4 & 40.4 \\
L3 & 29.3 & N7 & 18.4 \\
L8 & 24.6 & S1 & 43.0 \\
XW2 & 22.6 & S3 & 48.2 \\
XW5 & 30.6 & W4 & 37.7 \\
XW8 & 34.4 & HP4 & 31.2 \\
X1 & 20.0 & H5 & 29.2 \\
\hline
\end{tabular}


解能力测定, 结果有 18 株菌种有显著的降解 MC 能力. 图 2 是几株 MC 降解菌作用后 MC-LR 变化的 HPLC 图谱. 在 MC-LR 为 $15 \mathrm{mg} / \mathrm{L}$ 时, 菌种 X1、W4、S3 显示了不同的降解能力, 其中 S3 的降解去除 MC-LR 的能 力较强, 菌种 X1 降解能力较弱. 表 1 所列为 18 株菌种的降解率, 其降解能力在 $18.4 \%$ 到 $48.2 \%$ 之间. 本文 选取降解能力相对较强的五株菌 S3、S1、N1、N4 和 W4 进行研究, 其分解能力分别为 $48.2 \% 、 43 \% 、 41 \%$ 、 $40.4 \%$ 和 $37.7 \%$.
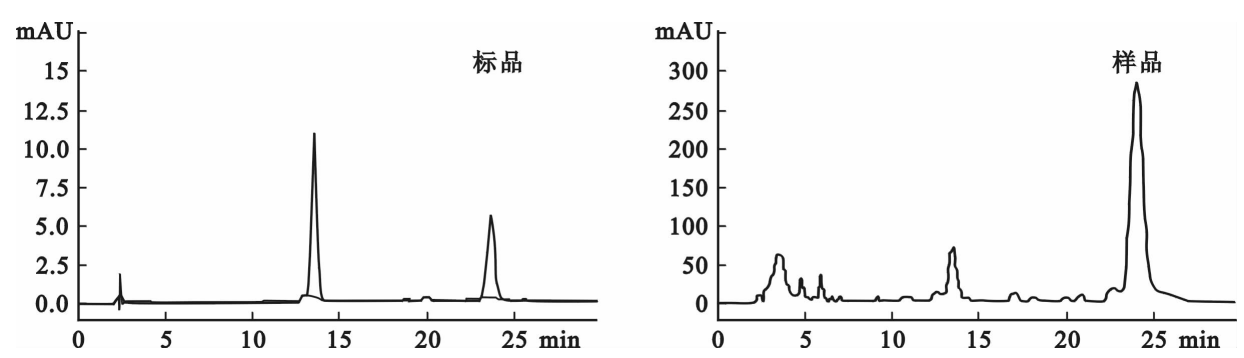

图 $110 \mathrm{mg} / \mathrm{L}$ 标品和提取的样品 HPLC 出峰图谱

Fig. 1 HPLC profiles of standard MC-LR and MC-RR of $10 \mathrm{mg} / \mathrm{L}$, and extracted and purified MC
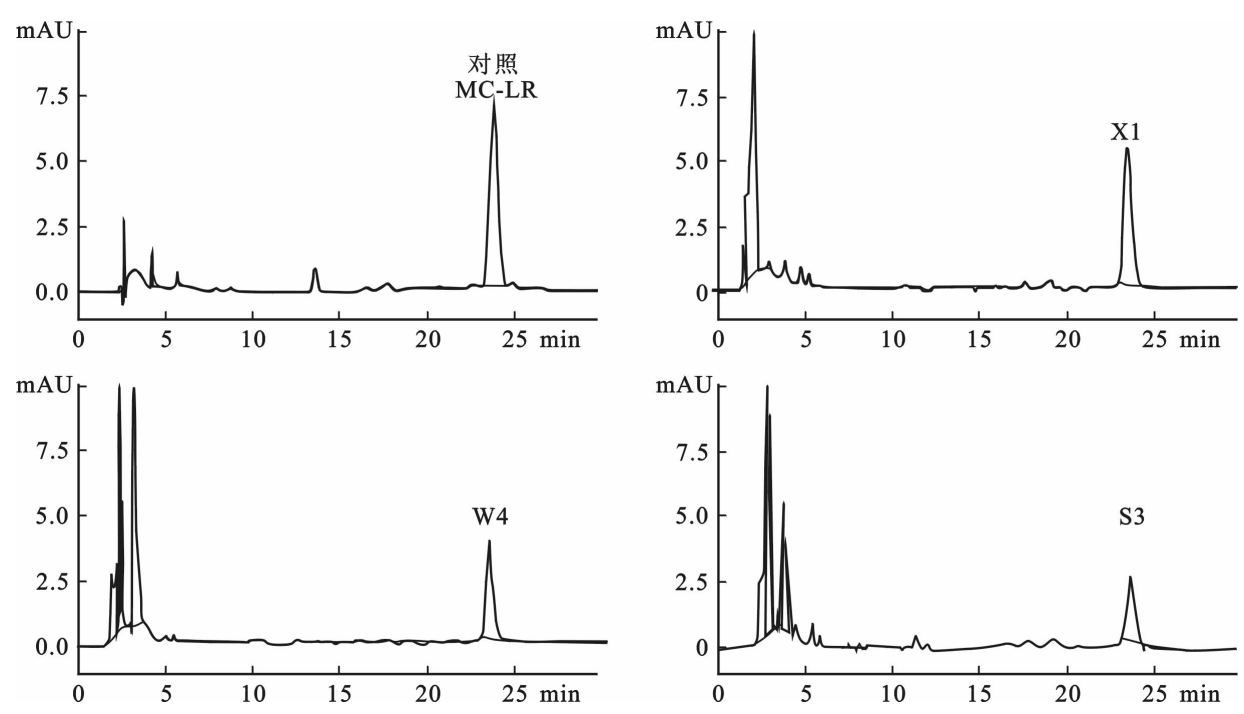

图 2 不同菌种降解 MC-LR 的 HPLC 图谱

Fig. 2 HPLC profiles of MC-LR biodegradation by different isolated bacterial strains

\subsection{MC-LR 降解菌的鉴定}

2.3.1 菌体形态和培养性状 5 株菌种在牛肉膏蛋白胨培养基上培养 $24 \mathrm{~h}$, 按照革兰氏染色法区别 5 个菌 株, 有 3 个菌株呈革兰氏阴性反应, 2 个菌株呈革兰氏阳性反应. 经显微镜观察, 5 个菌株均呈杆状. 将分离 纯化的菌种在牛肉膏蛋白胨培养基上在 $30^{\circ} \mathrm{C}$ 培养 $48 \mathrm{~h}$ 后观察记载, 5 个菌株在培养基上各呈不同的表现 (表 2).

2.3.2 生理生化特征 五株菌种具体生理生化特征见表 3. 
表 2 MC-LR 降解菌形态特征及培养性状

Tab. 2 Morphological and cellular characteristics of bacterial strains for degrading MC-LR

\begin{tabular}{|c|c|c|c|c|}
\hline 菌 株 & 菌体形状 & 革兰氏染色 & 鞭 毛 & 培养性状 \\
\hline $\mathrm{S}_{1}$ & 杆状 & $\mathrm{G}^{-}$ & 无 & 菌落白色, 半透明, 近圆形, 周缘光滑, 中间乳状突起 \\
\hline $\mathrm{S}_{3}$ & 直杆 & $\mathrm{G}^{-}$ & 周生 & 菌落较大, 白色, 周缘光滑, 圆形湿润, 中间乳状突起 \\
\hline $\mathrm{W}_{4}$ & 长杆状 & $\mathrm{G}^{+}$ & 无 & 菌落较小, 灰白色, 近圆形, 菌落较粘, 中间乳状突起 \\
\hline $\mathrm{N}_{1}$ & 直杆 & $\mathrm{G}^{+}$ & 无 & $\begin{array}{l}\text { 菌落较大, 浅黄色,近圆形, 周缘光滑, 中间有乳状突起, } \\
\text { 菌落较粘,液体培养产生絮状沉淀. }\end{array}$ \\
\hline $\mathrm{N}_{4}$ & 直杆 & $\mathrm{G}^{-}$ & 无 & 菌落红色, 圆形, 周缘光滑, 湿润, 有光泽 \\
\hline
\end{tabular}

表 $3 \mathrm{MC}$ - LR 降解菌生理生化测定试验结果

Tab. 3 Results of physiological and chemic tests of bacterial strains for degrading MC - LR

\begin{tabular}{|c|c|c|c|c|c|}
\hline 生理生化反应 & $\mathrm{S}_{1}$ & $\mathrm{~S}_{3}$ & $\mathrm{~W}_{4}$ & $\mathrm{~N}_{1}$ & $\mathrm{~N}_{4}$ \\
\hline 芽孢染色 & - & - & - & + & - \\
\hline 抗酸染色 & - & - & - & - & - \\
\hline 苂光色素 & - & - & - & - & - \\
\hline 脓青素 & - & - & - & - & - \\
\hline $\mathrm{KCN}$ 生长 & - & + & - & - & - \\
\hline 运动性 & - & + & - & - & - \\
\hline 柠檬酸盐 & + & + & + & - & + \\
\hline 丙二酸盐 & - & + & - & - & - \\
\hline 氧化酶 & - & - & - & + & - \\
\hline 接触酶 & + & + & + & - & + \\
\hline 脲酶 & - & - & - & - & - \\
\hline 脂酶 & - & - & - & - & - \\
\hline 葡萄糖氧化 & + & + & + & + & - \\
\hline 葡萄糖发酵 & - & + & - & - & - \\
\hline 甲基红 & - & - & - & - & - \\
\hline VP 测定 & - & + & + & + & - \\
\hline 硝酸盐还原 & - & + & - & - & - \\
\hline 形成吲哚 & + & + & + & + & + \\
\hline 苯丙氨酸脱氨酶 & - & - & - & - & - \\
\hline 明胶液化 & + & + & - & + & + \\
\hline $\mathrm{H}_{2} \mathrm{~S}$ 产生 & - & - & - & + & - \\
\hline 乙醇氧化 & - & - & - & - & + \\
\hline 乙酸氧化 & - & - & - & - & - \\
\hline
\end{tabular}

2.3.3 菌株鉴定结果 根据对其培养性状、菌体形态、染色反应、生理生化性状进行的系统试验. 结果表明, 上述 5 株细菌初步鉴定为不动细菌属 (Acinetobacter)、肠杆菌属 (Enterobacter)、微杆菌属 (Microbacterium) 、 芽孢杆菌属 (Bacillus)、弗拉特氏菌属 (Frateuria). 进一步的鉴定还需要结合 16SrDNA 序列分析来判断该菌 株的种类.

\section{3 讨论}

滇池、太湖等湖泊中微囊藻水华的爆发使水体中含有较高浓度的微囊藻毒素. 这些湖泊也是周边城市 
的饮用水源. 在现有的自来水生产工艺中,无法去除水中的毒素. 要减少毒素的威胁,应对水源中的毒素进 行特殊处理. 本文分离获得了几株具有较高微囊藻毒素降解能力的细菌, 为利用微生物消除毒素提供了可 能. 由于来自于土著菌群,所以这些菌株有较好的环境兼容性.

从本研究分离获得的 MC 降解菌结果来看, 具有分解 MC 能力的细菌广泛存在于各种微囊藻水华发生 的水体中,初步分析鉴定出的五株细菌分别属于不同的属种,这些种类不同于已报道的种类. 不同种类 $\mathrm{MC}$ 降解菌的广泛存在, 为在不同环境条件下利用微生物降解微囊藻毒素提供了选择.

上文中所列出的毒素降解率是一个相对值, 仅表明在本研究的笁选条件下相对的降解能力, 本文仅选 择了 5 株具有显著高的降解能力的菌进行了鉴定, 对这 5 株菌的进一步研究尚在进行中.

\section{4 参考文献}

[1] 张维昊, 徐晓清, 丘昌强. 水环境中微囊藻毒素研究进展. 环境科学研究, 2001,14(2): $57-61$.

[2] Ito E, Takai A, Kondo F, et al. Comparison of protein phos-phatase inhibitory activity and apparent toxicity of microcystins and related compounds. Toxicon, 2002,40(7):1017 - 1025 .

［3］中华人民共和国卫生部. 生活饮用水水质卫生规范,卫法监发 [2001 ] 161 号,2001.

[4] Chorus I \& Bartram J, Toxic Cyanobacteria in Water: A guide to their public health consequences, monitoring and management. F \& FN Spon, 1999, WHO.

[5] 朱光灿,吕锡武. 去除藻毒素的水处理技术进展. 中国给水排水,2003, 19(8):36-39.

[6] 金丽娜,张维昊, 郑利等. 滇池水环境中微囊藻毒素的生物降解. 中国环境科学, 2002,22 (2): 189 -192 .

[7] Park H D, Sasaki Y, Maruyama T, et al. Degradation of the cyanobacterial hepatotoxin microcystin by a new bacterium isolated from a hypertrophic lake. Environ Toxicol, $2001,16(4)$ : 337 - 343.

[8] Shigeyuki T, MariyoF W. Microcystin LR degradation by Pseudomonas aeruginosa alkaline protease. Chemosphere, 1997, 34(4):749-757.

[9] 间 海,邓义敏,邹 华等. 降解微囊藻毒素菌种的笁选和活性研究. 环境科学, 2004,25(6):49-53.

[10] 李 祝, 郭向前, 赵以军等. 水环境中微囊藻毒素的生物降解. 生态科学, 2005,24(1):90-95.

[11] Linda A L, Christine E. Purification of microcystins. J Chromatogr A , 2001,912 : 191 - 209.

[12] Hiroshi I, Miyuki N, Toshihiko A. Characterization of degradation process of cyanobacterial hepatotoxins by a gram-negative aerobic bacterium. Water Research,2004,38:2667 - 2676.

[13] 东秀珠,蔡妙英. 常见细菌系统鉴定手册. 北京:科学出版社,2001.

[14] 中国科学院微生物研究所细菌分类组. 一般细菌常用鉴定方法. 北京:科学出版社,1978.

[15] 布坎南 R E, 吉本期 N E. 伯杰氏细菌鉴定手册,第八版. 北京:科学出版社, 1984 . 